\title{
Point of Care OGTT for the screening of Gestational Diabetes: a feasible proposal for low resource settings
}

Dr Héctor Gallardo Rincóna, Dr Julieta Lomelín Gasconª, Dr Luis Alberto Martinez Juarezb, DSc Airaín Alejandra Montoya Rodríguezª Dr Enrique Reyes Muñozc, Dr Roberto Tapia-Conyera.

Affiliations:

aCarlos Slim Foundation

bMexican Society of Public Health

cNational Institute of Perinatology (Mexico)

Project funded by Global Health Partnership Eli Lilly \& Company

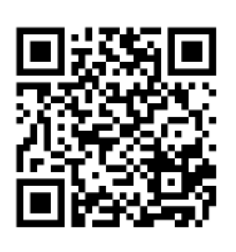




\section{FINANCIAL DISCLOSURE}

Presenter: Dr Luis Alberto Martinez Juarez ${ }^{b}$

Dr Martinez declares to be working in a project funded by Global Health Partnership Eli Lilly \& Company

\section{Co-authors:}

Dr Héctor Gallardo Rincón ${ }^{a}$

Dr Julieta Lomelín Gascona

DSc Airaín Alejandra Montoya Rodrígueza

Dr Enrique Reyes Muñozc

Dr Roberto Tapia-Conyera

\section{Affiliations:}

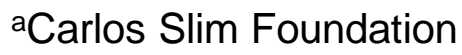

bMexican Society of Public Health

cNational Institute of Perinatology (Mexico)

Drs Gallardo, Lomelin, Montoya, Reyes, and Tapia-Conyer have no conflicts of interest 


\section{BACKGROUND / OBJECTIVE}

\section{Rationale}

The global prevalence of Gestational Diabetes Mellitus (GDM) is estimated to be between 7.5 and $27 \%{ }^{1}$.

The information available in Mexico is not sufficient to measure the national prevalence of GDM, however it is estimated that it varies between 10 and $12 \%{ }^{2,3}$.

Screening and diagnostic strategies have been the subject of international debate. At this time the oral glucose tolerance test (OGTT) is considered the Gold Standard for the diagnosis of GDM.

The American Diabetes Association (ADA) recommends three venous plasma glucose samples (fasting, $1 \mathrm{~h}$ and $2 \mathrm{~h}$ after the intake of $75 \mathrm{~g}$ of glucose $)^{4}$. This criteria has been recommended for the diagnosis of DMG in Mexico ${ }^{2,5}$.

However, it is difficult to perform the GDM screening in many low-resource settings due to limited access to standardized laboratories.

\section{Objective}

To compare the efficacy of two point of care (POC) models for GDM detection against the plasmatic $2 \mathrm{hr}$ OGTT-75gr in primary health care clinics in Mexico. 


\section{METHODS AND MATERIALS}

We evaluated 328 pregnant women without a previous diagnosis of diabetes from a prospective cohort study 'Cuido mi embarazo'.

All participants were tested with the gold standard plasmatic $2 \mathrm{hr}$ OGTT-75g for the diagnosis of GDM between the 24th and 28th weeks of pregnancy.

The diagnosis was made based on the criteria of the ADA 2020 , which is the same diagnostic criteria recommended by Mexican guidelines.

Simultaneously, we measured with a glucometer (AccuChek Instant $($ ) ) the glucose concentration either by venous whole blood (156 measures) or by capillary whole blood (172 measures).

We evaluated the diagnostic accuracy by calculating the sensitivity, specificity, and area under the Curve (AUD) of ROC curve of each of the glucometer models compared to the $2 \mathrm{hr}$ OGTT-75g (Gold Standard).
328 pregnant women without previous diagnosis of diabetes

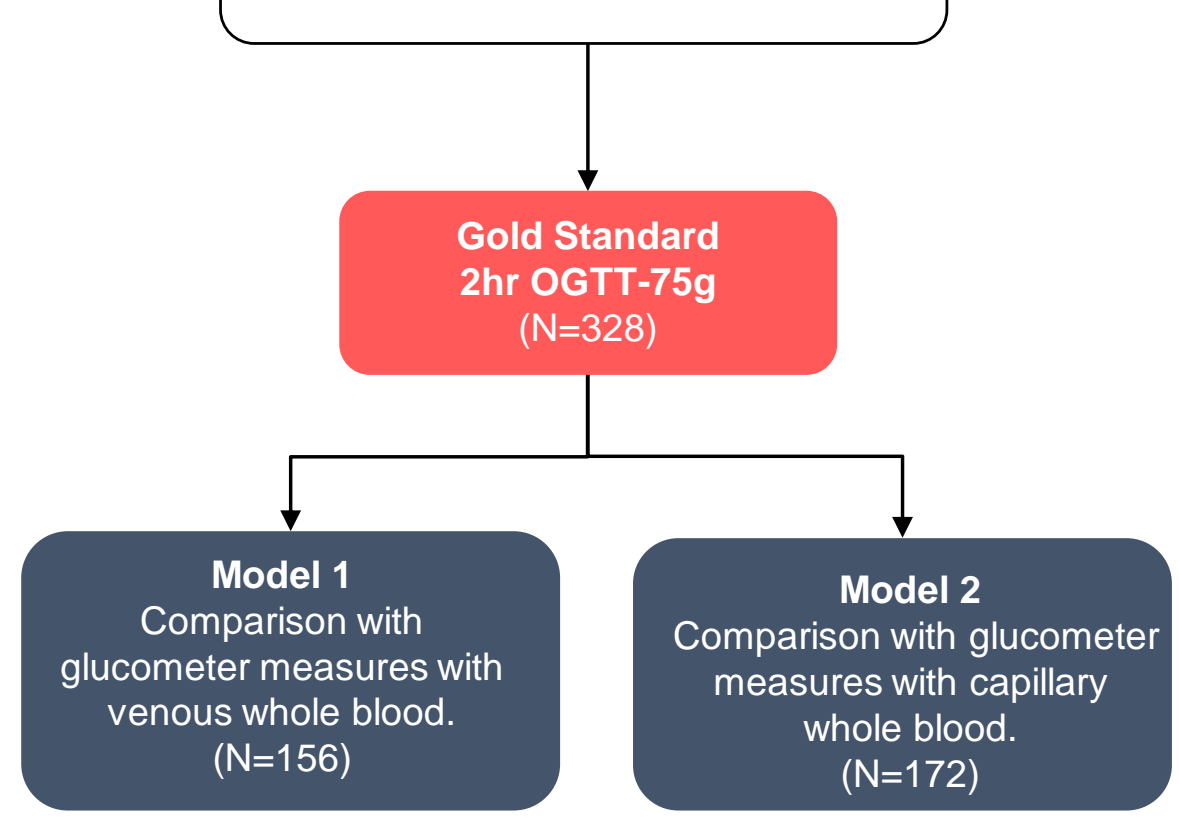




\section{RESULTS}

\section{Model 1 (Venous blood analyzed by glucometer)}

Table 1. AUC of ROC curve, sensitivity and specificity of Model 1 with respect to the Gold Standard

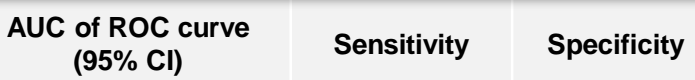

Analysis of model 1
0.81
$(0.77-0.85)$

$100 \%$

$62.8 \%$

Table 2. Pearson correlation coefficient, AUC of ROC curve, sensitivity and specificity by each glucose measurements with respect to the Gold Standard

\begin{tabular}{|c|c|c|c|c|c|}
\hline $\begin{array}{l}\text { OGTT } \\
\text { Measurement }\end{array}$ & $\begin{array}{c}\text { Pearson } \\
\text { correlation } \\
\text { coefficient }\end{array}$ & $\begin{array}{c}P \\
\text { value }\end{array}$ & $\begin{array}{c}\text { AUC of } \\
\text { ROC curve } \\
(95 \% \mathrm{Cl})\end{array}$ & Sensitivity & Specificity \\
\hline Fasting value & 0.62 & \multirow{3}{*}{$<0.05$} & $\begin{array}{c}0.81 \\
(0.77-0.85)\end{array}$ & $100 \%$ & $63.5 \%$ \\
\hline Value $1 \mathrm{hr}$. & 0.94 & & $\begin{array}{c}0.97 \\
(0.95-0.99)\end{array}$ & $100 \%$ & $95.2 \%$ \\
\hline Value $2 \mathrm{hr}$. & 0.93 & & $\begin{array}{c}0.98 \\
(0.97-0.99)\end{array}$ & $100 \%$ & $97.3 \%$ \\
\hline
\end{tabular}

Figure 1. AUC of ROC curve of Model 1 and each glucose measurements with respect to the Gold Standard

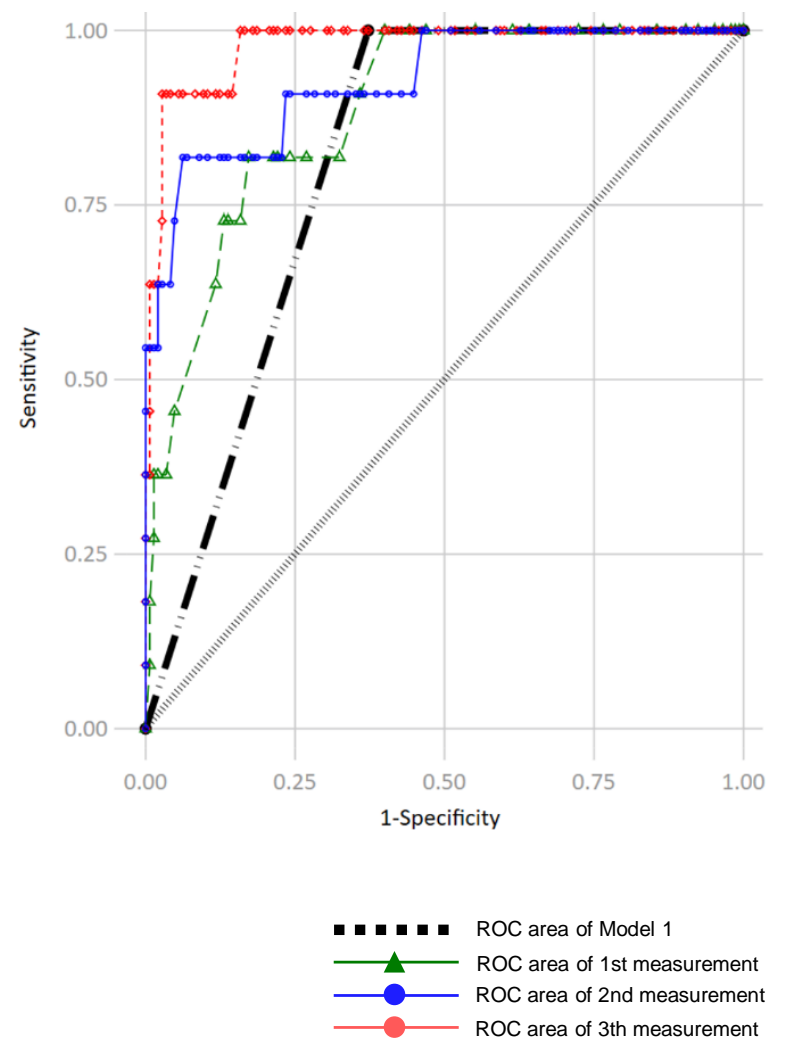




\section{RESULTS}

\section{Model 2 (Capillary blood analyzed by glucometer)}

Table 3. AUC of ROC curve, sensitivity and specificity of Model 2 with respect to the Gold Standard

\section{AUC of ROC curve $(95 \% \mathrm{Cl})$ \\ Sensitivity \\ Specificity}

Analysis of model 2
$78.5 \%$

$74.1 \%$

Table 4. Pearson correlation coefficient, AUC of ROC curve, sensitivity and specificity by each glucose measurements with respect to the Gold Standard

\begin{tabular}{|l|c|c|c|c|c|}
\hline $\begin{array}{l}\text { OGTT } \\
\text { Measurement }\end{array}$ & $\begin{array}{c}\text { Pearson } \\
\text { correlation } \\
\text { coefficient }\end{array}$ & $\begin{array}{c}\text { P } \\
\text { value }\end{array}$ & $\begin{array}{c}\text { AUC of } \\
\text { ROC curve } \\
\text { (95\% Cl) }\end{array}$ & Sensitivity & Specificity \\
\hline Fasting value & 0.42 & & $\begin{array}{c}0.77 \\
(0.65-0.89)\end{array}$ & $76.9 \%$ & $77.9 \%$ \\
\hline Value 1 hr. & 0.56 & $<0.05$ & $\begin{array}{c}0.76 \\
(0.52-1.00)\end{array}$ & $60.0 \%$ & $93.4 \%$ \\
\hline Value 2 hr. & 0.53 & & $\begin{array}{c}0.72 \\
(0.23-1.00)\end{array}$ & $50.0 \%$ & \\
\hline
\end{tabular}

Figure 2. AUC of ROC curve of Model 2 and each glucose measurements with respect to the Gold Standard

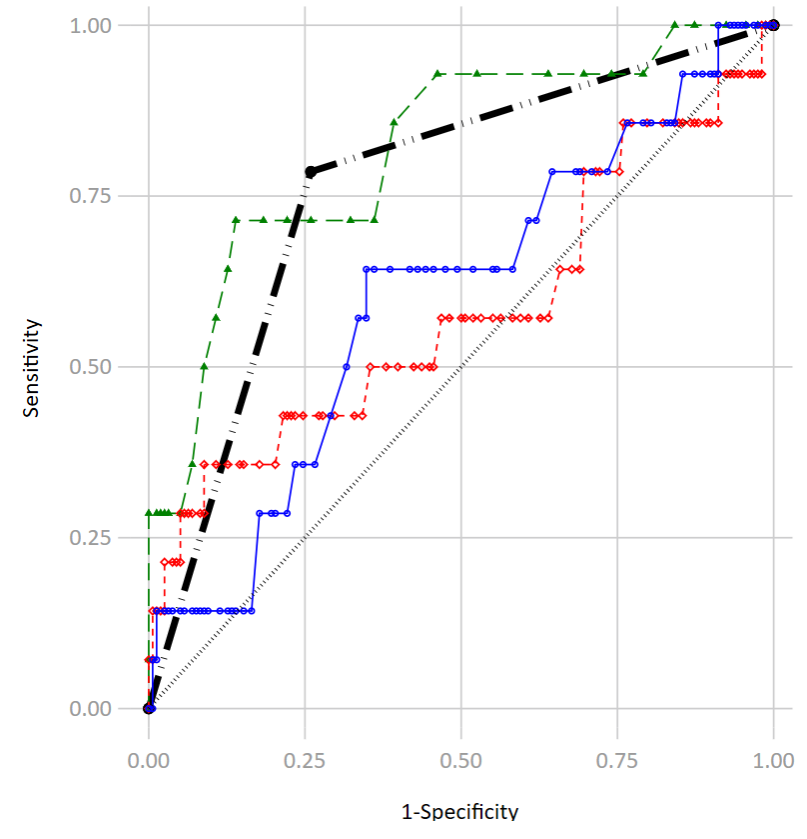




\section{CONCLUSION AND DISCUSSION}

This analysis conducted within the Cohort 'Cuido mi Embarazo' in Mexico aims to analyze alternative strategies for GDM screening.

The models we studied are based on the use of a glucometer. The first model focused on performing the OGTT with venous whole blood without the need to have a laboratory installed. The second model was considered for those situations where it is only possible to have capillary glucose measurements.

Based on our preliminary results, the sensitivity and specificity of both models suggest an opportunity to use alternative methods to the Gold Standard where this test cannot be performed.

In particular, Model 1 (with an AUC of ROC curve of $0.81 ; 95 \% \mathrm{Cl}: 0.77-0.85$ ) shows to be a good alternative screening strategy by using the same reference values for the diagnosis of GDM than the Gold Standard.

However, we must consider that the use of capillary blood is operationally easier to use in low-resource settings. It requires less training, is minimally invasive, is portable, is better accepted by the patient and is cost-effective ${ }^{6}$. Some studies suggest the consideration of capillary blood glucose as a screening alternative for GDM with adequate sensitivity and specificity ${ }^{7-9}$

This analysis suggests that Model 2 (with an AUC of ROC curve of 0.76 ; $95 \% \mathrm{Cl}$ : $0.64-0.87$ ) has good specificity to be considered as a screening strategy for GDM by using the same reference values than the Gold Standard.

It is necessary to carry out additional sensitivity and specificity studies considering different glucose reference values to increase their respective diagnostic capacity. 


\section{REFERENCES}

1. International Diabetes Federation. Hyperglycaemia in pregnancy (HIP) (20-49 y): Prevalence of gestational diabetes mellitus (GDM) [Internet]. [cited 2020 May 18]. Available from: https://diabetesatlas.org/data/en/indicators/14/

2. Centro Nacional de Equidad de Género y Salud Reproductiva. Diabetes y Embarazo: Lineamiento técnico [Internet]. Ciudad de Mexico; 2017 [cited 2020 May 18]. Available from: http://cnegsr.salud.gob.mx/contenidos/descargas/SMP/LineamientoDiabetesyEmbarazo.pdf

3. Reyes-Muñoz E, Parra A, Castillo-Mora A, Ortega-González C. Effect of the diagnostic criteria of the international association of diabetes and pregnancy study groups on the prevalence of gestational diabetes mellitus in urban mexican women: A cross-sectional study. Endocr Pract. 2012 Mar 1;18(2):146-51.

4. American Diabetes Association. 2. Classification and Diagnosis of Diabetes: Standards of Medical Care in Diabetes-2020. Vol. 43, Diabetes care. NLM (Medline); 2020. p. S14-31.

5. Secretaria de Salud de Mexico. ALGORITMOS DE ATENCIÓN CLíNICA: EMBARAZO [Internet]. Ciudad de Mexico; 2019 [cited 2020 May 18 ]. Available from: http://educads.salud.gob.mx/sitio/recursos/EMBARAZO.pdf

6. Dacus J, Schulz K, Averill A, Sibai B. Comparison of Capillary Accu-Chek Blood Glucose Values to Laboratory Values. Am J Perinatol. 1989;6(3):334-6.

7. Kumar G, Sng BL, Kumar S. Correlation of Capillary and Venous Blood Glucometry with Laboratory Determination. Prehospital Emerg Care. 2004 Oct 1;8(4):378-83.

8. Balaji V, Madhuri BS, Paneerselvam A, Arthi T, Seshiah V. Comparison of venous plasma glucose and capillary whole blood glucose in the diagnosis of gestational diabetes mellitus: A community-based study. Diabetes Technol Ther [Internet]. 2012 Feb [cited 2020 May 13];14(2):131-4. Available from: http://www.ncbi.nlm.nih.gov/pubmed/21992269

9. Bhavadharini B, Mahalakshmi MM, Maheswari K, Kalaiyarasi G, Anjana RM, Deepa M, et al. Use of capillary blood glucose for screening for gestational diabetes mellitus in resource-constrained settings. Acta Diabetol [Internet]. 2016 Feb 28 [cited 2020 May 13];53(1):91-7. Available from: http://link.springer.com/10.1007/s00592-015-0761-9 